\title{
LA ACADEMIA DE MINAS DE POTOSÍ. LA CORTA TRAYECTORIA DE UNA INSTITUCIÓN MINERA, 1779-1782*
}

\author{
POTOSÍ'S MINES ACADEMY. THE SHORT TRAYECTORY \\ A MINING INSTITUTION, 1779-1782
}

María Concepción Gavira Márquez**

\begin{abstract}
Este trabajo aborda la fundación de la Academia de Minas de Potosí en 1779 por el gobernador Jorge Escobedo y analiza sus características y condiciones con el objeto de poder evaluar el impacto que tuvo en la minería y sociedad potosina. A diferencia de la importancia y trascendencia del Real Seminario de Minería novohispano, la Academia de Potosí tuvo una corta vida y en consecuencia un escaso impacto. Nos parece importante comparar las dos instituciones dedicadas a la instrucción y educación de los jóvenes mineros para analizar sus particularidades y considerar las causas por las que una institución fue exitosa y la otra fue un proyecto fracasado. Hemos anexado las Ordenanzas de la Academia creadas por el gobernador Escobedo con el fin de poder dar a conocer lo que consideramos una debilidad de la institución, su programa y estructura interna, especialmente si la comparamos con el caso novohispano.
\end{abstract}

Palabras claves: Minería colonial, instituciones mineras, política minera colonial, Potosí.

This work addresses the founding of Potosi's Mines Academy in 1779 by Governor Jorge Escobedo and analyzes its characteristics and conditions in order to evaluate the impact it had on the mining and society of Potosí. Unlike the importance and transcendence of the Real Seminario de Minería Novohispano, the Academy of Potosí had short life and consequently low impact. It seems important to us compare the two institutions, both dedicated to instruct and educate young miners, analyze their particularities and consider the reasons why one was successful while the other was a failed project. We have annexed the Ordinances of the Academy created by Governor Escobedo in order to be able to analyze and make known what we consider a weakness of this institution, its program and internal structure, especially if we compare it with the Neohispanic case.

Key words: Colonial mining, mining institutions, Potosí.

\section{Introducción}

Son escasas las referencias en la historiografía colonial a la Academia de Minería de Potosí, y la razón es sencilla pues gozó de una corta vida y un escaso impacto en la sociedad y minería del Potosí del siglo XVIII. A diferencia de lo que ocurrió, por ejemplo, con el Colegio o Seminario de minería novohispano, la Academia potosina no puede considerarse que tuviera los resultados que se propuso el gobernador Jorge Escobedo, fundador de la institución. En este trabajo vamos a intentar explicar precisamente el porqué de su fracaso. Abordaremos la fundación de la Academia, sus características y las circunstancias en que fue abierta y el corto tiempo que perduró. Nos interesa saber por qué no tuvo el impacto que consiguió el Seminario de Minería de la Nueva España, conocer las semejanzas y las diferencias entre las dos instituciones. El Seminario de Minería novohispano fue una institución exitosa con una larga e importante trayectoria en la sociedad y la minería novohispana y mexicana; sin embargo la potosina fue una institución frustrada desde sus inicios.

La historiografía novohispana se ha encargado en diferentes estudios de analizar el Seminario de Minería, institución nacida a partir de una serie de reformas muy importantes y vinculadas con el auge de la producción minera en el virreinato de Nueva España (Izquierdo 1958, Flores Clair 2000, Escamilla y Morelos 2017). El Real Tribunal de minería, las Ordenanzas de Minería de 1783, el Banco de avío, las Diputaciones mineras, estas medidas estaban destinadas a reformar y fomentar la actividad minera y aunque discutidas a veces por su grado de eficacia, no dejan de ser consideradas muy importantes por su impacto en el sector económico y las relaciones que generaban en su entorno (Flores Clair 2000 y 2001). El mismo Humboldt (1811: 227) destacaba el Colegio por su importancia y

\footnotetext{
* Investigación desarrollada en Sevilla (2017-18) y aprobada por el CONACyT durante estancia investigativa.

** Universidad Michoacana de San Nicolás de Hidalgo, Facultad de Historia, Morelia (México). Correo electrónico: cagaviram@ hotmail.com
} 
reconocía que "Ninguna ciudad del nuevo continente, sin exceptuar las de los Estados Unidos, presenta establecimientos científicos tan grandes y sólidos como la capital de México".

A partir de la aprobación de las Ordenanzas de Minería de la Nueva España en 1783, se comunicó a los virreyes de Perú y del Río de la Plata la necesidad de adaptar estas ordenanzas para implementar las reformas destinadas a fomentar esta actividad, y entre las instituciones programadas se contaba con el Real Seminario de Minería, llamado Colegio de Minería a partir de la independencia de México. Sin embargo, en el virreinato del Río de la Plata, el primer proyecto de la Academia de Minería fue anterior a estas medidas (1757), como veremos a continuación, y la fundación de la institución por el gobernador Escobedo se realizó en 1779, casi en paralelo al primer proyecto del Seminario de Minería de la Nueva España que retrasaría su apertura hasta 1792. Sin embargo debemos señalar que el gobernador de Potosí no estaba al tanto del proyecto novohispano cuando pidió aprobación a la Corona, como lo demuestra la correspondencia de José Antonio Areche y Jorge Escobedo (AGI, Charcas, 437 A y B).

En este trabajo nos aproximaremos a los orígenes de los distintos proyectos en los territorios americanos de los colegios, escuelas, academias o seminarios, y sus características como instituciones que consiguieron un mayor o menor éxito. Sabemos que fueron instituciones distintas en su origen e independientes, como fue el caso de la Academia de Minas de Potosí y el Seminario de Minería de México, de las que nos interesa analizar qué tan destacadas eran sus particularidades a pesar de desarrollarse en un contexto político común. En todo caso en la segunda mitad del siglo XVIII los vientos de la Ilustración llegaron hasta los territorios americanos y se desarrollaron muchos proyectos como ocurrió en Guatemala en 1749 o en 1776 en Lima. Sin embargo, estos proyectos no se realizarían de forma inmediata (Molina 1977).

La historiografía minera colonial, como por ejemplo Buechler (1989) y Tandeter (1992), ha señalado el fracaso de la Academia de Minas de Potosí, poniendo especial atención en las disputas entre autoridades y la difícil coyuntura política y económica de Potosí, pero creemos necesario analizar también desde dentro sus particularidades para entender las debilidades que minaron la viabilidad de la institución. Un estudio clásico de Guillermo
Ovando Sanz (1975) acerca de la Academia de Minería de Potosí como origen de la Escuela de Minas y más tarde Facultad de Ingeniería, nos muestra una descripción y relación de documentos vinculados al origen y fundación de la Academia, pero sin ningún tipo de análisis ni cuestionamiento respecto de su gestión o eficacia, pero a pesar de ello se agradece la transcripción de la documentación colonial. En un trabajo de Purificación Gato Castaño (1994) se aborda la fundación de la Academia como uno de los proyectos del gobernador ilustrado Jorge Escobedo, pero sin entrar en el análisis más detallado de la institución potosina.

Una primera parte de este trabajo abordará una aproximación a los distintos proyectos americanos desde sus orígenes, poniendo más atención en el novohispano y potosino, para adentrarnos posteriormente en las particularidades de la Academia de Potosí y el análisis de su corta vida, así como las ordenanzas que se aprobaron en 1779 , cuya transcripción nos ha parecido conveniente adjuntar al trabajo.

\section{Los vientos europeos y la Ilustración}

El siglo XVIII, especialmente durante su segunda mitad, es conocido por el impulso que tomaron las ciencias, especialmente aquellas disciplinas que eran reconocidas por su importante utilidad. La metalurgia fue una de estas disciplinas desarrolladas con gran intensidad en las distintas regiones mineras de Europa. Sin duda fue durante el reinado de Carlos III cuando se dio un mayor impulso a las ciencias y tecnología en España y América. Respecto de la minería hay que destacar la apertura de la Escuela de minas de Almadén en 1777 dirigida por Storr. Estos años fueron de mucha intensidad en cuanto a la producción de conocimientos científicos y su difusión, había entonces una gran admiración por las matemáticas y una red de comunicación admirable entre la comunidad de científicos europeos (Muñoz Dueñas 1992: 29). La Academia de Almadén y el Seminario de Vergara recibieron una notable influencia de la Academia de Freiberg, donde estudiaron los hermanos Elhuyar, Andrés Manuel de Río y el mismo Humboldt (Escamilla y Morelos, 2017: 41). En 1788 se designaba a Francisco de Angulo como Director General de Minas, el que fue alumno de Freiberg donde también se formaron otros jóvenes que fueron profesores en Almadén a fines del siglo XVIII y principios del XIX (Sumozas, 2007). 
Los dos hermanos Elhuyar fueron el mejor ejemplo del ambiente ilustrado de fines del siglo XVIII y de la difusión y comunicación en su más amplia concepción (Palacios Remondo, 1994). Fueron formados en Europa, recorrieron la mayoría de los centros donde se innovaba y se aplicaban nuevas tecnologías, y posteriormente viajaron hasta América como directores de una comisión en 1789 de expertos europeos que tuvieron un reto importante, mostrar la mayor eficacia del método de amalgamación con barriles (Bargalló, 1955). Los expertos tuvieron que comparar las dos tecnologías: el método de patio americano y el de los barriles de Born. Al final, no pudieron salir airosos y tuvieron que reconocer como lo hizo Sonneschmidt las ventajas del método de patio de amalgamación con azogue ${ }^{1}$.

La necesidad de consolidar el conocimiento en minería no fue exclusiva de Europa, en los territorios americanos desde mediados del siglo XVIII empezaron a evidenciarse la necesidad de fundar escuelas o colegios que difundieran la tecnología y conocimientos en minería. En 1749 en Guatemala se produjo un proyecto de escuela de minas protagonizado por José Eustaquio de León que quedó frustrado por su muerte y resurgió en 1792 (Molina, 1977: 127). Sabemos poco de este proyecto pero De León era ensayador de la Caja Real de México y pasó a ser en 1731 nombrado director de la Casa de la Moneda de Guatemala, es decir, se trataba de un profesional experto en la fundición y el ensaye pero sin experiencia académica (Cano Borrego, 2016). Miguel Molina (1977: 127) destaca en diferentes estudios, como los proyectos para crear un Colegio de Minería en Lima fueron obstaculizados por diferentes motivos: falta de capital, oposición de los mineros o circunstancias adversas. Entre las primeras tentativas, según este autor, se encuentra en 1776 la propuesta de Juan Gregorio Piñeyro y Sarmiento, el que tampoco llegó a pasar de simple proyecto. Años más tarde, en 1789, José de Lagos presentaba un "Proyecto económico a favor de los indios y habitantes del Perú" que incluía un Colegio de Minería (Molina, 1977:128). Este proyecto contaba con más detalles respecto de número de profesores, sueldos, alumnos, etc. Los costos de dicha institución se elevaban a 27.400 pesos, y estaba previsto que contara con 48 alumnos, quedando excluidos los mulatos pero incluía a los indios y mestizos. Según Molina, esta cuestión se contradecía con lo estipulado en las Ordenanzas de Nueva España, en la que no estaban contemplados los mestizos ni los indios. Este fundamento ayudó a que quedara en una simple tentativa.

El siguiente intento en el virreinato peruano sería el propuesto por Jorge Escobedo después de salir de Potosí en 1786. El proyecto fue diseñado con un costo menor y sostenía 4 profesores y 8 alumnos, pero el Tribunal de Minería no lo apoyó por falta de fondos. Posteriormente con la llegada del virrey Gil y Lemos en 1790 se intentó de nuevo promover el colegio y poner al frente al recién llegado barón Nordenflicht pero la escasez de capital lo pospuso. El siguiente proyecto, que tampoco resultó, fue ideado por el mismo barón Nordenflicht y se denominó Escuela teórico-práctica para formación de químicos, metalúrgicos, ensayadores y beneficiadores (Molina, 1977).

En todo caso nos interesa destacar un detalle importante que retomaremos más adelante, el único proyecto que se consolidó y fue un éxito respecto de las instituciones americanas, fue el Seminario de Minería de México. En su origen se contaban expertos en minería y en su ejecución Fausto de Elhuyar, personaje de gran conocimiento y experiencia en la minería, metalurgia, y también con experiencia docente y académica. Consideramos que este será un factor decisivo para la consecución del proyecto.

\section{El antecedente: "La Junta o Escuela" fundada por el corregidor de Potosí Ventura Santélices en 1757}

Anterior al proyecto de la Academia que fundó el gobernador Escobedo en 1779, encontramos la fundación de una institución poco conocida que llegó a considerarse una especie de Escuela donde experimentar y preparar a los mineros y beneficiadores de Potosí. Esta "Junta o Escuela", como fue denominada por el gobernador de Potosí Ventura Santélices, quedó constituida formalmente en 1757. Este proyecto fue incluso anterior al que plasmaron los novohispanos Lucas de Lassaga y Joaquín Velázquez de León en 1774 en la famosa Representación ${ }^{2}$, cuando pedían autorización para fundar un Colegio o Seminario Metálico donde preparar a los jóvenes que algún día dirigirían la minería novohispana ${ }^{3}$. El gobernador Santélices también observó la necesidad de enseñanza y preparación para los integrantes y trabajadores del 
gremio minero, constituyendo una escuela compuesta por un director y seis maestros o expertos. Esta Escuela fue considerada por Ovando Sanz (1975) como la primera Escuela de minería de América, sin embargo hay que reconocer que son pocos los documentos que nos permiten reconstruir sus características y su efímera vida. Debemos señalar cierta confusión en sus orígenes, así como su composición y su forma de operar.

Considera Ovando Sanz (1975) como el primer documento origen de esta Escuela el testimonio de una reunión donde el gobernador Ventura Santélices hace comprometerse a Domingo Tenorio y Joaquín Bravo a realizar experimentos con metales negrillos y llevar anotaciones al respecto. Este documento está fechado el 11 de junio de 1757 y pocos días más tarde, el 17 de junio quedaba constituida la "Junta o Escuela". En este documento el gobernador haciéndose eco de los perjuicios que generaban la falta de preparación de la gente dedicada a la minería y señalando de forma especial el problema de beneficiar los metales negrillos, metales ricos que tenían más dificultad y requerían de mayor pericia para tratarlos, vio la necesidad de preparar a los expertos en este procedimiento. El gobernador aludía a los problemas provocados por la "ignorancia" de los azogueros y mineros que terminaban generando conflictos y juicios al no saber considerar los límites y rumbos de las minas. Según el gobernador de Potosí, de estos problemas se derivaban graves gastos en mano de obra, desperdicios en el azogue consumido y la sal. Todo ello decía que se podría remediar estableciendo:

"una Junta o Escuela, en que concurra un director de ella, dos sujetos de alguna inteligencia chimica para el buen análisis de los metales, dos que se escojan inteligentes en el mineraje y dos en el beneficio y sujeto que haga de escribano para escribir y recoger todos los discursos u observaciones que hicieren, para que todos los lunes por la tarde confieran en el ingenio que se les señale y asienten sus principales discursos y ensayes..."

El 18 de junio de 1757 el gobernador escribía dando conocimiento de haber dictado en un auto el día anterior de la necesidad de "principiar el establecimiento de una junta o escuela para lograr la inteligencia tan conveniente en la saca y beneficio de metales de este cerro..." (AGI, Charcas, 470). Informaba que nombró como director a Salvador García Ponce, "atendiendo a su conocida erudición, a su inteligencia práctica en el mineraje y a la que tiene en los negocios de ambas Américas", y para los otros 6 empleos se nombraron a Gregorio Yrigoyen, "dueño de minas en ingenios en el paraje de Guariguari", Domingo Serrano, Joaquín Bravo, "azoguero y dueño de ingenio", Juan de Neish, Domingo Tenorio, "beneficiador de negrillo acreditado en Oruro", y Bautista Lacoa "por su respectiva inteligencia en las partes del mineraje", y como secretario Nicolás Pacheco. El lugar asignado para esta escuela y para los experimentos era el ingenio Cuti (AGI, Charcas, 470).

Según la opinión de Ventura Santélices, esta junta de expertos contaba de "dos personas peritas en la Chímica, de dos mineralogía, de dos en el beneficio de la plata y el oro", sin embargo no sabemos cómo estaban distribuidas estas cualidades entre los designados ${ }^{5}$. El objetivo principal que se propuso el corregidor era mejorar el beneficio de minerales negrillos ${ }^{6}$, y así se jactaba de "ganar la mitad de tiempo que antes se registraba, excusar a los indios el mucho trabajo y sacar a los metales alguna más ley" (AGI, Charcas, 470. Expediente 29 y 30. Informe de Ventura Santélices, Potosí, 25 de junio de 1757).

Ovando Sanz incluye documentos transcritos, los mismos que se encuentran en el Archivo General de Indias y además alude a cierta información procedente de las publicaciones de Armando Alba, el que señala la existencia de ocho alumnos pero no precisa más detalles ni referencias (Ovando Sanz, 1975:5).

Se trataba por tanto de una Junta o Escuela experimental con principios prácticos y utilitarios. No tenemos noticias de enseñanza de materias teóricas, como química o matemáticas, ni de horario de clases, ni de la duración de la formación. La docencia estaba a cargo de unos personajes que no pueden argumentar más allá de ser "dueños de ingenios" o tener experiencia como beneficiadores. Pocos años más tarde cuando desde la Península se requería información al virrey de las actividades de esta Junta y los resultados, este comunicaba a la Corona que no había adelantos concretos. El siguiente gobernador San Just no continuó con el proyecto (AGI, Charcas, 470. Exp. 29 y 30, fechas 1757-1762). 


\section{La fundación de la Academia de Minas de Potosí en 1779}

No cabe duda que los personajes que están detrás de los proyectos académicos fueron decisivos a la hora no solo de organizarse sino también de conseguir cierta aceptación y operatividad de la misma institución. El gobernador Jorge Escobedo, nacido en Jaen de familia noble, recibió formación en Salamanca y perteneció al grupo de reformistas comisionados en el virreinato del Perú para realizar una visita y poner en marcha un importante paquete de medidas tendentes a mejorar el gobierno y administración de las colonias ${ }^{7}$. En 1776 se le confirió la plaza de oidor de la Audiencia de Charcas y pocos meses después se le asignaría el corregimiento de Potosí en dependencia de la visita de Areche. Su paso por Potosí fue muy fructífero, su mayor logro radicó en la incorporación del Banco de Rescate a la Corona, pasando a denominarse el Real Banco de San Carlos. Esta institución, la reconstrucción del Real Socavón de Potosí y la Academia de Minería fueron tres ejes principales durante su gobierno en Potosí (Tandeter, 1992 y Buechler, 1989).

El 10 de febrero de 1779 el gobernador Jorge Escobedo reunía a los azogueros y les daba un discurso titulado Sobre la utilidad y medios de fomentar el trabajo de minas y beneficio de metales en la imperial villa de Potosi $^{8}$ (AGI, Charcas, 425), con el que inauguraba la Academia de Minería y presentaba las ordenanzas. Durante este año de 1779 consultó y gestionó con las altas autoridades de Lima y de la Península pidiendo apoyo para hacer funcionar el proyecto, el que ya tenía alumnos. A principios de 1779 Escobedo expuso al visitador del Perú José Antonio Areche, al que le tenía en gran consideración, su proyecto de la Academia y le contó cómo aprovechó la presencia en Potosí del beneficiador portugués Antonio Silva para nombrarlo maestro, ante su prestigio y éxito en el mineral de Aullagas. Reunió al gremio de azogueros y les comunicó su propuesta, para ello contaba con la financiación del Banco de San Carlos, lo que fue muy discutido. La propuesta de Silva como maestro estaba argumentada en su éxito en minerales vecinos y en una opinión bastante particular. Decía el gobernador Escobedo que este maestro beneficiador era el más a propósito "por sus modales y crianza y honrado porte para dar formalidad al establecimiento" (AGI, Charcas, 437 A, N. 3. Escobedo al visitador general José Antonio
Areche, Potosí 21 de junio de 1779), y le comentaba a Areche que los beneficiadores y mineros potosinos iban vestidos de andrajos, "borrachos no pocas veces e incapaces de decir buenos días" (AGI, Charcas, 437 A, N. 3. Escobedo al visitador general José Antonio Areche, Potosí 21 de junio de 1779). Los novohispanos Lassaga y Velázquez de León tenían la misma opinión de los "sujetos" dedicados a la minería, "gente de baja extracción, y vil crianza" (Flores Clair 2000: 29), por tanto la enseñanza y preparación de los alumnos en cualquiera de los proyectos tenía un mismo objetivo principal: hacer de los estudiantes interesados en la minería hombres con cultura y educación a la vez que expertos en la minería. Escobedo en su discurso de apertura de la Academia (Ovando Sanz, 1975: 87), incitaba a los azogueros a solucionar todos los males a partir del conocimiento, de la instrucción. Manifestaba en el mejor estilo de político ilustrado, los conocimientos y avances de los últimos tiempos y aludía a científicos como Homberg (química), Haller y Boerabo (botánica) Noled y Bellidor (física e hidráulica). También en su discurso consideraba el importante papel de las Reales Sociedades y Academia de Madrid (Gato Castaño 1994: 200).

A las explicaciones de Escobedo, el visitador Areche le respondía que no consideraba excesivo el sueldo de Silva, ni "la instrucción con las lecciones de la obra de Barba" (AGI, Charcas 437 A. Carta de José Antonio Areche a Jorge Escobedo. Lima, 23 de mayo de 1779), pero decía que la falta de enseñanza de la materia de química, tan importante en esta actividad, sería muy discutida. Escobedo le contestó, "el auxilio de la química bien ponderé su necesidad en mi discurso pero no hay quien pueda darlo, ni en el día pudieran avenirse a unas operaciones cuya prolijidad les haría desmayar" (AGI, Charcas 437 A. Carta de Escobedo a Areche, Potosí 21 junio de 1779). Aquí radica una de las importantes debilidades del proyecto de Escobedo. La Academia era un proyecto puramente experimental.

José Antonio Areche continuaba poniendo al tanto al gobernador del proyecto de Seminario de Minería que se elaboraba en Nueva España, el que como sabemos no se hizo efectivo hasta 1792. Describía brevemente el programa de enseñanza del seminario novohispano, decía que un primer maestro debía enseñar las materias: español, aritmética, geometría, trigonometría y álgebra; el segundo maestro mecánica, maquinaria, hidroestática, aerometría y pirotecnia; el tercer maestro la química teórica y 
práctica, y el cuarto la mineralogía y metalurgia y también dibujo. El colegio de minería incluiría a 25 alumnos dotados con 300 pesos, se le asignaba un total de 27 mil pesos (AGI, Charcas 437 A. Carta de Areche a Escobedo. Lima, 23 de mayo de 1779). Sin embargo como bien señala Eduardo Flores, este Colegio o Real Seminario de Minería fue muy discutido en un principio y aunque se basó en el proyecto de Lassaga y Velázquez de León, demoró su apertura hasta 1792 debido a la muerte de los dos expertos en $1786^{9}$. Hubo que esperar también hasta la llegada del nuevo director general nombrado por la Corona, Fausto de Eluyar, quien contaba con una gran experiencia y el apoyo de la Corona. José Antonio Areche le explicaba también a Escobedo que por entonces junto con este Colegio se proyectaba un Tribunal de Minería, y un Banco de Avío. Todas estas instituciones fueron las que se pondrían en marcha a partir de la aprobación de las Ordenanzas de Minería de Nueva España de 1783.

El gobernador de Potosí se asombraba de la magnitud del proyecto novohispano, del que no tenía noticias, y se quejaba de que su humilde proyecto encontrara tantos obstáculos. Escobedo incluso contaba en su carta que estaba costeando a algunos alumnos de su bolsillo ${ }^{10}$. Nos parece significativo la justificación que daba sobre la decisión de elegir y fundamentar toda la enseñanza en la obra de Álvaro Alonso Barba. Decía que Potosí era un lugar difícil con gente muy especial y el maestro Alonso Barba era conocido y respetado en la villa imperial por haber trabajado en el Alto Perú ${ }^{11}$.

Hay que reconocer que el programa de la Academia era bastante escueto y reiterativo basándose únicamente en la obra de Alonso Barba. Según el Título cuarto de las ordenanzas (véase anexo), el primer año los alumnos copiarían la obra de Alonso Barba y el segundo año volverían a Barba y el tercer año estudiarían más Barba. Tres años en total, donde no habría más teoría o materia que la recogida por el famoso licenciado en la obra El arte de los metales, a la que no quitamos mérito por su importancia pero no debería ser un conocimiento exclusivo.

"Las Ordenanzas de la Academia y Escuela Teórico Práctico de Beneficio de metales" que Escobedo ponía bajo advocación de San Juan Nepomuceno como protector se aprobaron en diciembre de 1779 y tan solo se señaló lo oportuno de añadir una ordenanza para que pudiera adjuntarse o cambiar lo que se considerase necesario para la institución con la observación de que para ello debía obtenerse la aprobación de más de la mitad de los votos y el beneplácito de la Corona.

\section{Distintos proyectos y distinta trayectoria: México y Potosí}

Después de observar algunas diferencias entre ambas instituciones que surgieron con poco más de una década de diferencia, profundizaremos un poco más en las cuestiones internas en cuanto al programa académico, la docencia, así como becas, y recursos. Debemos reconocer que el origen de estas diferencias radicaba en su mayor parte en la cabeza de los proyectos. Escobedo no dejaba de ser un político, un personaje versado en leyes con actitudes de político ilustrado que consideraba importante los cambios y la normatividad para un buen gobierno, sin embargo no tenía capacidad para organizar una institución con una estructura académica sólida. Fausto Elhuyar sin embargo tenía toda la preparación científica necesaria para organizar la academia, además de la experiencia y de su capacidad de gestión. Flores Clair (2000: 42) y Escamilla y Morelos (2017) señalan la influencia de las academias europeas en el colegio novohispano, y ciertamente esto se lo debemos a Elhuyar, el que salió victorioso del debate que se originó con la creación del Real Seminario o Colegio dentro del Tribunal de Minería. No cabe duda de que en América la metalurgia experimental había consolidado el método de patio, el que no pudo superarse por los expertos alemanes que llegaron a fines del siglo XVIII, pero se necesitaba consolidar los conocimientos teóricos.

Los planes de estudio del Real Seminario novohispano sufrieron algunas alteraciones desde 1792 hasta 1821, pero básicamente planteaban unas materias teóricas y prácticas y se requerían seis años para completar la enseñanza y se exigía una tesis para la titulación (Izquierdo, 1758). Las asignaturas principales eran: Matemáticas, Física, Química y Mineralogía; las auxiliares: Dibujo, Francés, Gramática castellana, Geografía, Lógica, Religión y Política. En referencia a la Academia de Potosí debemos señalar que tan solo contaba cuando se fundó con un maestro metalúrgico que era Silva. Según el título $3^{\circ}$ de las Ordenanzas, las características del Maestro consistían: "buenas costumbres, crianza, aplicación e inteligencia que sepa leer, escribir y contar...”. El método a seguir 
por el docente queda estipulado en el siguiente título $4^{\circ}$ y consistía en estudiar la obra de Alonso Barba durante los tres años de la docencia. Escobedo no dejaba de reconocer la importancia de la química pero justificaba su ausencia diciendo que no había quien impartiera la materia. En 1779 le comentaba a José de Gálvez "lo oportuno e interesante" que expertos de Sajonia y Alemania fueran a Potosí, tal como sugirió el virrey del Perú, y pudieran ser maestro en la Academia. Sin embargo no puso mucho interés en justificar la necesidad de maestros expertos y la enseñanza de materias como la química, física o matemáticas (AGI, Charcas, 437 A).

La planta docente del Colegio novohispano estaba compuesta de personajes con una trayectoria importante en cada una de sus áreas temáticas. Flores Clair recoge la relación de profesores y las materias que impartían, algunos muy conocidos y reputados científicos: el mismo Fausto Elhuyar impartió química, Luis Lindner, Andrés del Río... La selección del cuerpo docente fue a veces difícil, pues Elhuyar tenía preferencia por los europeos, aunque con el paso del tiempo modificó sus criterios y se apoyó en los alumnos egresados del Real Seminario (Flores Clair, 2000: 146-165).

Los sueldos de los profesores variaban según la materia impartida. En México los maestros de asignaturas principales como la física, química y mineralogía y matemáticas cobraban entre 1.500 y 2.000 pesos y los de auxiliares entre 300,400 y 1.000 pesos (Flores Clair, 2000: cuadro 8: 168). En Potosí solo constaba el maestro portugués Silva, el que cobraba 3.000 pesos que salían de la aportación de los azogueros en el Banco de San Carlos. Las capacidades y preparación del portugués no eran muy formales pero Escobedo argumentaba sobre su elección:

"no me atreveré a decir que Silva sea consumado en el arte ni capaz de toda la enseñanza a que se aspira pero entre los beneficiadores del país lo tengo por los más hábiles y el más apropósito por sus modales y crianza y honrado porte para dar principio con alguna formalidad al establecimiento" (AGI, Charcas, 437A)

Pero según la información facilitada del gobernador en una carta a José de Gálvez fechada en abril de 1781, decía que "el maestro de la Academia se ha despedido solicitando irse a otro temperamento por hallarse en este casi baldado y echando sangre por la boca" (AGI, Charcas, $437 \mathrm{~B}, \mathrm{n}^{\circ} 78$. Escobedo a Gálvez, 16 de abril de 1781). También hay que destacar la poca estabilidad y formalidad de la docencia a juzgar por las salidas del maestro Silva que era requerido para hacer estudios y experimentos fuera de Potosí, por ejemplo su estadía en Porco en 1781(AGI, Charcas, 438). En todo caso, según los testimonios con que contamos, estimamos que el maestro Silva estuvo en la Academia de Potosí como dos años aproximadamente. El último documento que conocemos firmado por Antonio Silva fue el 31 de diciembre de 1780 (AGI, Charcas, 437A) y después de este profesor no conocemos ningún remplazo. Se habla de maestros en las Ordenanzas pero solo se sabe de uno, el que es el único que aparece en el documento al final de dicho reglamento (véase anexo).

Por otra parte, en las ordenanzas de la Academia de minas de Potosí aparecen establecidos algunos miembros de los cuales no se percibe claramente su función y su sueldo; por ejemplo además del director, cuatro azogueros del ilustre gremio de azogueros de Potosí, dos diputados del mismo gremio, el ensayador de la Casa de la Moneda, el oficial de la Caja Real de Potosí, el director del Real socavón, un censor y un secretario (véase las Ordenanzas, el título $1^{\circ}$ ).

Respecto de los alumnos del Colegio novohispano, debemos señalar que fueron seleccionados después de cumplir unos requisitos que quedaron establecidos desde muy pronto y que se recogieron por Elhuyar en unas instrucciones en 1791 que se reformaron y ampliaron posteriormente en 1803 (AHPM, 1803-II-120-d.6). En un principio no estaba permitido que entraran mestizos pero la presión obligó a acabar con esta exclusión social. De hecho, quedan en el Archivo Histórico del Palacio de Minería un número importante de expedientes de limpieza de sangre donde los alumnos debían certificar ser descendientes legítimos de matrimonio de españoles, o de nobles indios, estar bautizados y porvenir de familia minera. También debían demostrar saber leer, escribir y tener conocimientos de "las cuatro reglas de las matemáticas y los quebrados". Este estatuto de limpieza de sangre que había sido una herramienta de exclusión religiosa en España, en América sería utilizado para la exclusión étnica (Böttcher, Hausberger y Hering, 2011). La edad requerida a los muchachos era de 14 a 20 años. Según 
Flores Clair (2000:113) por las aulas del Colegio pasaron 333 alumnos en el periodo de 1792 a 1820.

En la Academia de minas se estipulaba que debían entrar 12 estudiantes en su comienzo y 6 cada principio de año. Las exigencias para el ingreso son menores que en México, "deben saber leer y escribir y contar medianamente", no se especifica de otras operaciones como en la novohispana acerca del conocimiento de los quebrados. Se admitirían alumnos de fuera de Potosí y pagarían 100 pesos para gastos de los maestros. El tiempo para alcanzar la titulación sería de tres años y los horarios en la Academia de 8 a 10 y de 2 a 4 de la tarde. Al igual que en la institución novohispana se tenían establecidos unos premios a la invención o adelantamientos que se consideraran dignos de este honor, pero es significativo que en las Ordenanzas de la Academia de Potosí aparezca un señalamiento que aludía a la no discriminación: "se admitirán indistintamente de dentro y fuera de este mineral, sin diferencia de clases ni sexos y los que aspiren a conseguirlos deberán presentar su proyecto escrito, entregándolo cerrado, firmado y rubricado" (Ordenanzas, título $5^{\circ}$ ).

A diferencia del caso potosino, en el Real Seminario quedaron muchas evidencias de la reglamentación y de todo el proceso de aceptación de los alumnos. Los diferentes tipos de alumnos debían cumplir los requisitos recogidos en la Ordenanzas de minería. El Tribunal debía admitir a 24 alumnos becados originarios equitativamente de todas las diputaciones territoriales mineras. También se contemplaban lugares para alumnos pensionistas que debían pagar 150 pesos anuales y alumnos externos. Todo ese proceso generó mucha información que ha sido analizada por el historiador Flores Clair (109-142). Sin embargo, respecto de los alumnos que entraron en la Academia de minas de Potosí nada sabemos, y como no había una reglamentación clara de los requisitos se nos hace todavía más difícil conocer cómo fue el proceso de elección de los alumnos y quién tenía las competencias para llevarlo a cabo. Lo que consideramos poco probable es que se admitieran alumnos de los centros mineros de provincias o de otras regiones de Charcas, o del virreinato del Río de la Plata, pues como ya hemos comentado en otros trabajos Potosí siempre monopolizó las ayudas de fomento de la actividad minera (Gavira, 2007 y 2011). El gremio de azogueros siempre fue muy celoso a la hora de compartir sus prerrogativas.

La financiación del Real Seminario novohispano corría a cargo del Tribunal de Minería y estaba estimada en un principio en 25.000 pesos, aunque algunos años, especialmente en la primera etapa, según Flores Clair (2000), los gastos superaron los 33.000 pesos para verse reducidos a partir de 1811 . No tenemos evidencias de la financiación exacta de la Academia durante esos tres escasos años.

El 31 de agosto de 1781 Gálvez le comunicaba a Escobedo que el Rey estaba enterado de los progresos de la Academia (Ovando Sanz, 1975:128); ¿pero cuáles eran esos progresos? Se trataba de los experimentos que Silva había realizado en la Casa de la Moneda y en Porco $^{12}$ con el beneficio de sus metales (AGI, Charcas, 437 B). Por lo visto, no se trataba de los adelantamientos propios de una Academia o Escuela que debería estar enfocada a la formación y preparación de los alumnos. En todo caso, este tipo de actividades suponemos que afectaba en el desarrollo estable de las clases al tener que ausentarse el único maestro de la institución.

\section{La salida del gobernador Jorge Escobedo y los nuevos proyectos}

Poco sabemos de la vida de la Academia después de la salida de Potosí del gobernador Escobedo y el nombramiento del nuevo gobernador intendente Juan del Pino Manrique. En febrero de 1782 Escobedo le dejaba un resumen de su gobierno y las cosas pendientes al sustituto, y en este documento le recomendaba que cuidase la Academia, reconocía sus limitaciones pero decía que ninguna institución importante se consolidaba en un día. Pero consciente de sus carencias también consideraba la necesidad de reforzar el proyecto para que se acercase más a los objetivos de una Academia que lo que hasta entonces venía funcionando:

\footnotetext{
“...siendo mi idea el que viniendo de Europa algunos extranjeros de honor y consumada pericia en este arte, se entablase un colegio donde puestos laboratorios químicos $\mathrm{y}$ otras oficinas de fundición, afinación y separación de metales se criasen algunos jóvenes enviando de cada mineral uno o dos que se mantuviesen a sus expensas" (AGI, Charcas, 435. Potosí, 11 de febrero de 1782).
}

La falta de evidencias nos sugiere que con la salida a Lima de Escobedo se acabó la vida de la Academia. El gobernador Pino Manrique en 1787 
hacía una nueva propuesta inserta en lo que se suponía que era una adaptación de las Ordenanzas de Minería de Nueva España al virreinato del Río de la Plata, "un colegio de enseñanza que igualmente ha de establecerse en esta capital", del que proponía su composición y sus costos en el siguiente cuadro:

\section{COLEGIO}

\begin{tabular}{lr}
\hline Rector & 800 \\
Capellán vicerrector & 500 \\
Profesor de matemáticas & 1.200 \\
Profesor de química & 1.200 \\
Doce alumnos (a 250 por alumno) & 3.000 \\
Portero & 150 \\
Dos criados & 600 \\
Cocinero & 200 \\
Médico, cirujano y botica & 800 \\
Total & 8.450 \\
\hline
\end{tabular}

Fuente: AGI, Charcas, 438, Del Pino a Gálvez, Potosí 16 de noviembre de 1787 .

Este proyecto formaba parte de "un plan" donde se establecían los gastos principales que supondría la adaptación de las Ordenanzas de Nueva España para la institución del Tribunal de Minería y el Colegio en Potosí. Pero cambiaron los planes y este gobernador salió en 1788 sin haber podido establecer las nuevas reformas incluidas en la nueva legislación.

Pocos años después desde la Península se enviaba una comisión de expertos europeos con la pretensión de modernizar la metalurgia americana. Nordenflicht lideraba la comisión destinada al virreinato peruano pero en última instancia se envió a realizar una corta estancia en Potosí, donde arribó en enero de 1789 y cuyos resultados fueron muy cuestionados ${ }^{13}$. En 1790 el barón Nordenflicht dijo que sería un gran placer fundar una Academia en Potosí, donde "he empleado los primeros cultivos por mi amor al Rey" (AGI, Charcas, 700. Potosí 1 de agosto de 1790, el barón Nordenflicht a Valdez). Esto lo dijo en la misma carta donde contaba que nada más llegar a Potosí se enfermó y tardó muchos días en recuperarse. Suponemos que fue puro discurso porque nunca se mostró contento en Potosí, pero volvió a intentar con más entusiasmo el proyecto de la Academia en Lima, aunque tampoco llegó a realizarse (Molina, 1977).

Las siguientes referencias a un proyecto de Academia o Colegio de minería se encuentran en el Código Carolino, cuya autoría se adjudica al asesor del intendente de Potosí, Pedro Vicente Cañete. José de Gálvez tenía previsto que las Ordenanzas de
Minería de Nueva España se adaptasen y fungieran en todo el territorio americano, pero en el caso del virreinato del Río de la Plata el gobernador intendente Pino Manrique argumentó que Potosí requería una legislación especial y así se promovió un Código específico para el virreinato del Río de la Plata, mientras en Chile y Perú se adaptaron las ordenanzas novohispanas. El Código Carolino autoría de Cañete, el que no llegó a aprobarse, tenía incluido, al igual que las Ordenanzas de Nueva España, un apartado acerca de la necesidad de formación de los mineros y azogueros (Título 9 y 10, Ovando Sanz, 1975: 132). El título 9, Ordenanza 33: "Se fundará en esta Imperial villa en el tiempo en que pareciere adecuado al virrey de Buenos Aires, un colegio Patrimonial para la enseñanza de jóvenes naturales de las provincias...". La escuela abierta de Mineralogía y Metalurgia sería de enseñanza pública, señalaba Cañete que habría libertad para todo aquel que quisiera asistir a las clases. Se contemplaban clases teóricas, en un primer curso mineralogía y el segundo año de física, el tercero docimacia y química metalúrgica, además de enseñar otras materias entre las que contempla: aritmética, álgebra, geometría, mecánica, hidráulica...El edificio para la escuela quedaba fijado en la Casa de la Moneda vieja (Ovando Sanz, 1975: 135).

\section{Conclusión: las causas del fracaso de la Academia}

A modo de conclusión intentaremos evaluar la Academia de Minas de Potosí, la que como los documentos nos evidencian tuvo una corta vida que estimamos de tres años, se fundó en febrero de 1779 y se concluyó con la salida de Jorge Escobedo de Potosí a principios de 1782. Es un hecho que el gobernador intendente Pino Manrique no le dio seguimiento y propuso cinco años más tarde de su llegada el presupuesto de una nueva institución que debía contemplarse en el proyecto de la adaptación de la nueva legislación. Posterior a 1783, fecha de las Ordenanzas de Minería de Nueva España, la institución de enseñanza quedaba vinculada a las medidas contempladas en esta nueva legislación.

El corto tiempo que estuvo vigente la Academia es en principio la manifestación más contundente que nos induce a pensar en la imposibilidad para generar un gran impacto, pues a lo sumo pudo terminar su programa una generación de estudiantes y, por tanto, el alcance de los objetivos prioritarios como 
institución de educación y formación profesional fue muy limitado. Quizás sea necesario obtener más detalles de los alumnos inscritos y saber si terminaron sus tres años de formación y cuáles fueron sus trayectorias profesionales. Ciertamente la Academia como señalamos anteriormente no contemplaba un sólido programa de enseñanza y esta limitación la consideramos muy importante a la hora de la consecución de los principales objetivos: crear profesionales en el campo de la minería.

Respecto de las causas de su corta vida se han señalado diversas opciones que pudieron afectar para que no se consolidase. Ovando Sanz (1975:30) señala tres causas "preliminares" del fracaso de la Academia sin entrar en su análisis:

1 "La rebelión de los campesinos indios de 1780"14 2 "La creación del virreinato de Buenos Aires" 3 "La guerra hispano-portuguesa"

Por supuesto que estas tres causas externas no deben considerarse argumento suficiente para imposibilitar el desarrollo de una institución académica, como bien se evidenció con el Real Seminario de Minería novohispano, el que tuvo que superar coyunturas políticas y económicas bastante adversas y complicadas, prolongándose más allá de la guerra por la independencia. Debemos señalar que el Real Seminario de Minería, aunque nació como proyecto paralelo a la Academia de Escobedo (a fines de la década de los setenta), se abrió en 1792 cuando las Ordenanzas de Minería de Nueva España estaban en vigor y el Tribunal de Minería con Fausto Elhuyar a la cabeza apoyaba varias reformas y cambios que fueron decisivos para la minería novohispana y que están asociados al auge de este sector en el siglo XVIII. Sin embargo, a fines del siglo empezó a manifestarse cierto estancamiento y pocos años después de la apertura del Seminario comenzó un periodo de conflictos políticos que afectaron a la vida económica del virreinato novohispano, pero la institución minera perduró a pesar de la inestabilidad y violencia que conllevó la guerra por la independencia.
Un factor decisivo a nuestro juicio para el cierre de la Academia en Potosí fue la salida de Jorge Escobedo de Potosí, quien fuera su fundador y la autoridad más preocupada por mejorar la formación de los mineros y azogueros. Aunque le faltó una mayor y mejor perspectiva de las condiciones que requería la Academia de Minería, al menos dio un paso importante con la creación de la institución que pudo ir mejorándose en caso de haber sido posible consolidarla. Después de la salida de Escobedo, la nueva autoridad no le puso el mismo empeño a la institución, es conocida la situación complicada de Potosí con graves tensiones en el interior, pero también se consolidaron a pesar de ellas instituciones como el Banco de San Carlos fundado en 1779. Pero sin duda después del cierre de la Academia de Escobedo, el próximo proyecto de colegio de Minería estaría vinculado a una nueva legislación minera que finalmente no consiguió ponerse en vigor. Es posible que el gobernador Escobedo se adelantara en la puesta en marcha de la institución pero no podemos argumentar que le faltara el apoyo por parte de las autoridades peninsulares.

En marzo de 1786, a escasos años de la llegada a Potosí de Pino Manrique, el que fuera superintendente del Río de la Plata Francisco de Paula le comunicaba a este gobernador la voluntad del Rey para que las Ordenanzas de Nueva España se adaptasen al virreinato del Río de la Plata. En esta legislación estaba contemplado lo que supondrían grandes cambios como el Tribunal General de Minería, los Bancos de Avíos, las Diputaciones territoriales y el Colegio de Minería. En un primer momento, el gobernador se puso a la tarea pero pronto comunicó que no podía adaptarse esta legislación a las condiciones de la minería potosina. Por fin, con fecha del abril de 1787 la Corona proponía que se formaran unas Ordenanzas (Gavira, 2013) "acomodadas a esas provincias de Charcas" ${ }^{15}$. Este proceso tardó años y el Código Carolino donde estaba contemplado el Colegio de Minería, no se aprobó y por tanto quedaron en suspenso todas estas reformas que con mayor o menor éxito se lograron imponer en Nueva España y adaptarse en el virreinato peruano. 


\section{ANEXO DOCUMENTAL}

\section{ARCHIVO GENERAL DE INDIAS, SECCIÓN AUDIENCIA DE CHARCAS, LEGAJO 425. \\ CUADERNILLO, fojas 24-42}

\section{ORDENANZAS \\ DE LA ACADEMIA Y ESCUELA TEÓRICO PRÁCTICA DE BENEFICIO DE METALES ESTABLECIDA EN LA IMPERIAL VILLA DE POSOTÍ, EL AÑO DE 1779}

Teniendo esta fundación por su principal instituto el adelantamiento del Beneficio de metales y de todo lo que concierne a el más útil y acertado trabajo de la metalurgia para lograrlo es preciso estimular a los instruidos y hombres de talento de que no carecen estas provincias y al mismo tiempo facilitar la enseñanza de la juventud que son los fines que los mismos nombres de academia y Escuela expresan y a cuyo respeto se prescribirán las Ordenanzas o Constituciones que para este duplicado designio se contemplen más a propósito dividiéndolas en los títulos siguientes.

\section{TÍTULO $1^{\circ}$ \\ NOMBRE DE LA ACADEMIA NÚMERO DE ACADÉMICOS, EMPLEO Y SUS FUNCIONES}

Se ha de intitular la Academia y Escuela (25v) con el nombre del glorioso mártir San Juan Nepomuceno para que como especial protector de la honra y fama de sus devotos cuide de que la de esta fundación florezca bajo de sus auspicios.

2.

Supuesto el número que ahora se señala de Académicos, y no se debe hacer regla por ser extraordinario el caso de la formación en los sucesivo se compondrá de los que han de ser de número fixo y los supernumerarios.

3.

De número fixo han de ser siempre como más principales los quatro individuos más antiguos del Ilustre Gremio de Azogueros y los dos Diputados que sucesivamente lo sean del mismo Gremio, a que se añadirán por su inteligencia en metales los ensayadores de la Real Casa de Moneda, y Cajas y por lo que interesan el Rey y el público en el fomento de esta fundación lo serán también el más antiguo de los oficiales reales de estas Cajas y el
Procurador de la Villa que anualmente exerza este honroso empleo a que se agregara (26r.) el Director principal de la obra del socavón por la introducción que se le considera de la Geometría subterránea y luces que pueda administrar para el trabajo de las minas y el censor en caso de no ser alguno de los anteriores.

4.

En la clase de supernumerarios se admitirán todos los que por instrucción merezcan este distintivo y lo acrediten con laguna obra útil ya sea sobre el trabajo de minas y beneficio de metales o de alguna $\mathrm{u}$ otra cualesquiera industria que contribuya al ahorro de gastos de mayor perfección de los instrumentos necesarios sin excluir ninguna arte por la utilidad con que pueden construir al común alivio.

5.

Aunque todos contemplen dignos el título de académicos, siendo imposible comprehenderlo se han ceñido al número que ahora se señala y deberán pro esta ver reputarse de número fijo y asistir con voto en la forma que después se dirá a todas las juntas pero en lo sucesivo solo lo tendrán los del número fixo como queda insinuado. (26v.)

6.

Para la consideración y buen régimen de este cuerpo ha de haber siempre un director o presidente que sea su cabeza, un secretario, un censor y un diputado, sin que por ningún motivo se creen nuevos empleos.

7.

El Director y Presidente será siempre perpetuo y lo exercerá el señor ministro que Su Magestad tenga nombrado para las comisiones de esta Villa y en caso de estar divididas lo será por la conexión que tienen estas oficinas, el señor Superintendente del Banco como jefe más inmediato de la azoguería y en el mismo caso el señor Gobernador y demás ministros que pueda haber con destino en esta villa tendrán el título de Conciliarios no siendo creíbles que entre ministros del Rey y sujetos de tan llevado carácter haya etiquetas ni disputas que perjudiquen a el bien público y Real Servicio.

8.

El Director presidirá a todos los actos y funciones de la Academia y Escuela, cuidará de (27r) la asistencia de los Maestros y Diputados propondrá los medios que para el adelantamiento contemple oportunos ya sean partes de su celo y aplicación o sugeridos por otros de los mismos individuos o extraños pues a todos sería facultativo proponerlos al Presidente para que examinados reservadamente se 
conferencien después en junta de todos los vocales y en fin recibiendo toda la jurisdicción económica y gubernativa en la cabecera no habrá asunto en que no intervenga según corresponde.

9.

Los Conciliarios cuando por las insinuadas circunstancias haya estos empleos, asistirán voluntariamente a todos los actos logrando en sus asientos después del Director la preferencia debida a sus empleos y tendrán voto en todos los asuntos que se hayan en de determinar con este requisito.

10.

Secretario lo será uno de los individuos de número fixo el que se elija después del que ahora se nombra y lo exercerá perpetuamente a menos que por hacer renuncia o ausencia dilatada vaque el empleo o por su omisión merezca ser removido.

11.

Sera del cuidado del Secretario la custodia (27v.) de los libros, constituciones y acuerdos de la Academia, extender sus Juntas y recibir las cartas memoriales y memorias que se presenten a la Academia para darlas curso en la forma que después se dirá.

12.

Censor en vacando el que ahora se señala lo será el que se elija por los individuos de número fixo, aunque no sea de esta clase por ser preciso atender a la suficiencia que pide el desempeño de este encargo y por lo mismo sea perpetuo en la forma que el Secretario.

13.

Su oficio consistirá en censurar las obras que la Academia le encomiende y dar su parecer sobre su utilidad para hacer de ellas el uso que después paresca más acertado.

14.

Diputado se elegirá cada año de los individuos de numero fixo y será de su obligación desempeñar los encargos que por la Academia se le confían y atender la asistencia de los Maestros y Discípulos, visitando entre semana según lo permitan sus ocupaciones la casa destinada y a más representará (28r) todo el Cuerpo en los casos que a su nombre haya de practicar alguna diligencia que lo pida.

15.

Para alivio del Diputado y mayor esmero en la asistencia habrá un celador que sin elección lo ha de ser cada mes el azoguero en cuyo ingenio se esté practicando alguna experiencia y este cuidara de ella y deberá también en su mes estar a la mira de la Casa de la Escuela para celar la asistencia y participar inmediatamente a el Director los desórdenes omisiones y faltas que note.

16.

No se nombra tesorero porque de los caudales que puedan juntarse lo ha de ser siempre el que tenga igual empleo en el Banco de Rescates y su obligación será satisfacer hasta donde alcancen las libranzas que se expidan con las formalidades que se prevendrá.

17.

Se pone por ahora un maestro de beneficio de metales con la dotación correspondiente a sus obligaciones que después se prescribirán pero esto se variara en lo sucesivo según dicten los adelantamientos (28v.) progresos y aplicación que puedan fomentar a otros ramos de que ahora no se hace mención por la dificultad de poner la última mano en una obra nunca practicada y que solo se propone como bosquejo para empezar acomodándola a las actuales circunstancias del país y del tiempo que deberán perfeccionarla.

\section{TÍTULO $2^{\circ}$}

\section{EXERCICIOS DE LA ACADEMIA}

1.

Todos los meses habrá el jueves primero de cada uno, junta a que asistirán precisamente no teniendo lexítimo impedimento que se lo estorbe los individuos de número fixo y Maestros para informarse de cuanto en el mes se ha practicado y remediar las faltas de asistencia o abusos que puedan insensiblemente haberse introducido.

2.

Enterados del estado de aumentos o decadencia que se reconozca se trataran los medios de remediar esta o que continúe aquel y después (29r.) se oirá qualesquiera propuesta que se haga sobre beneficio de metales concerniente a las experiencias que sucesivamente han de irse practicando y deberán presentarse por escrito.

3.

Casa mes se hará una y ya sea siguiendo los métodos que a este fin traen Barba y Gamboa ya sea valiéndose de los manuscriptos y autores extranjeros o de las particulares invenciones que se hagan y puedan facilitar el continuado uso de las mismas experiencias.

4.

En estas Juntas se examinará el efecto que hayan tenido y deliberará si se han de repetir las 
minas en mes siguiente o variarlas y en qué forma e igualmente se señalará el ingenio en que se han de hacer que será siempre el de los más inmediatos a la villa para que su distancia no imposibilite la asistencia variándolos para hacer el común en esta corta pensión.

5.

Se escribirán estas Juntas en los libros destinados a este efecto con la separación que después se dirá. (29v.)

6.

A más de estas Juntas ordinarias habrá cada año en los meses de junio y diciembre dos extraordinarias, la primera para examinar los discípulos y la segunda para repetirlo, leer los adelantamientos de todo el año y las memorias que se hayan presentado y adjudicar los premios de que después se hablará.

7.

En todas estas Juntas y demás concurrencias que se ofrezcan sentándose a presidir el Director y a sus lados el Censor y Secretario y teniéndose presente la preferencia de los Conciliarios en caso de haberlos, los demás se sentarán indistintamente por obviar quejas dejando a la política y buena crianza que en todos se supone la urbana atención que piden estas concurrencias donde el más distinguido será siempre el que con mayor celo contribuya a los adelantamientos.

\section{TÍTULO $3^{\circ}$ \\ DEL MAESTRO DE LA ESCUELA, SUS OBLIGACIONES EN GRAL. \\ Y LAS QUE CORRESPONDE RESPECTO DE LA ACADEMIA Y DISCÍPULOS (30r.) \\ 1.}

El Maestro a quien más que el sueldo debe estimular su propio honor se elegirá siempre de buenas costumbres, crianza, aplicación y inteligencia que sepa leer, escribir, y contar, para que de este modo salgan los discípulos con la instrucción christiandad y buena fe que tanto importa para su exercicio.

2.

Jamás se empleará en utilidad propia de un solo individuo a menos que este tal tenga algún metal en que por común interés convenga lo dirija y en este caso será siempre por vía de experiencia.

3.

Será de su obligación ensayar por menor y por mayor los metales que a este efecto le presenten los individuos del ilustre Gremio y queriéndolo ellos darles la norma de su beneficio acudiendo el beneficiador de cada uno a enterarse de ella, avisar de los efectos o dificultades que ocurran y en estos casos dará alguna vuelta por el ingenio del interesado el mismo Maestro.

4.

Como su principal ocupación ha de ser el (30v.) adelantamiento por medio de las experiencias y enseñanzas de la juventud, dirigirá aquellas con arreglo a lo que en la Junta de cada mes se haya acordado en el ingenio que se eligiere cuyo dueño tendrá como queda dicho el cuidado de que se practique con puntualidad cuanto a este fin ordene y acabadas unas se pasará a otras entendiéndose en este sentido el espacio de un mes de que se ha usado por mayor explicación del método.

5.

Siendo tan falibles las experiencias por la multitud de casualidades que pueden variar sus efectos para darle mayor comprobante luego que el Maestro concluya unos en el ingenio señalado las repetirá el dueño con su beneficiador por las mismas reglas presentando al concluir razón jurada de todo lo que en ellas haya acaecido.

6.

Sin perjuicio de estas experiencias las practicará diariamente en su casa, así de fundición como de azogue, concurriendo en ellas todos los individuos que gusten del ilustre Gremio con (31 r.) sus beneficiadores a quien oirá con gusto y satisfará con su explicación las dificultades que puedan proponerles.

7.

Al mismo tiempo enseñará a los Discípulos, cuidará de su existencia, siguiendo el método del título siguiente.
TÍTULO $4^{\circ}$
MÉTODO DE LA ESCUELA HORAS DE ELLA, NÚMERO DE DISCÍPULOS Y SUS CUALIDADES
1.
Los Discípulos si fuere posible serán ahora doce y en lo sucesivo entraran seis al principio de
2.
Todos han de saber leer, escribir y contar me- dianamente y presentaran de su letra al Director memoriales de su pretensión para que vistos en la Junta General del fin de cada año se elijan los más idóneos en que se ha de atender sean de padres conocidos y honrados y si fuere dable de algunas conveniencias. (31 v.) cada año. 
3.

La elección de los de ahora se hará proponiendo cada uno de los académicos los que pueda hallar a propósito y que desde luego contribuye el Director ofreciendo uno y ayudarle si fuera preciso para su subsistencia.

4.

Para que se logre aprendan fundamentalmente este arte se seguirá el del doctor Barba y deberán asistir tres años a la Escuela en el modo siguiente.

5.

En el primero atendiendo a la falta que hay en exemplares impresos de esta obra y a que la aprendan con más facilidad y así mismo cursen la letra se les hará todas las mañanas escribir un capítulo de ella, dictando el Maestro u otro de quien pueda valerse a este fin y como los cinco libros del autor comprenden 112 capítulos que hacen 99 foxas, es fácil y de muy poco trabajo el que se copien en las mañanas de todo el año mayormente aquí donde son menos las fiestas de precepto que únicamente han de guardarse. (32 r)

6.

Escrita por la mañana esta breve lección a la tarde traerá el Maestro hacerles de ella una corta explicación procurándola aprendan de memoria y después que vean aquellas particularidades experiencias que dentro de su casa executa.

7.

En el segundo año escrita ya la obra volverán capítulo por capítulo a repasarla al mismo paso que la vayan escribiendo los nuevos Discípulos de aquel año de quien serán como pasantes y empleados prácticamente por el maestro en los ensayes y demás experiencias de dentro de su casa cuidará de hacérseles ver la aplicación de los mismos principios que han escrito y estudiado a el uso práctico de las operaciones.

8.

En el tercero repasarán las lecciones del mismo autor de los del segundo año y asistirán a las experiencias que se hagan en los ingenios valiéndose de ellos el Maestro, según la capacidad y aprovechamiento, que en cada uno haya notado y sufriendo en cada año los respectivos exámenes (32v.) en el último quedarán aprovechados según lo merezcan.

9.

Las horas de la asistencia han de ser por la mañana de ocho a diez y por la tarde de dos a cuatro, pues siendo estas sobradas para escribir y repasar la diaria lección es preciso dejar algunas desembarazadas a el Maestro si para las privadas experiencias de su Casa, como para el cuidado de las públicas, que por turno se vayan practicando en cada ingenio.

10.

El Maestro que voluntariamente o por vil codicia del mayor interés que pueda prometerse en otra parte no concluya los tres años expresados será borrado del número de académicos con la nota que corresponda a su ligereza o fea acción y en ningún tiempo será admitido en este cuerpo ni en el Gremio de esta Ribera.

11.

Si sucediere que alguno de los Maestros que ahora se señala o en adelante hubiere lo sonsacaren de otros Minerales haciéndole partidos (33r) ventajosos entendiéndose con el lo dicho en la ordenanza anterior, por lo que hace a el que lo solicite se recurrirá al Superior Gobierno por pronto remedio y después al Rey para que le impongan las penas correspondientes a un enemigo de la sociedad y perjudicial al bien público.

12.

Y porque no se crea que va a estancarse en este Mineral una ciencia que a todos es tan interesante se admitirán también Discípulos de afuera siendo de su cargo el mantenerlos y contribuir anualmente al fondo con 100 pesos por cada uno para ayudar a los sueldos de los Maestros y lo que según la multitud de Discípulos podría ser preciso aumentarles.

\section{TÍTULO $5^{\circ}$ \\ PREMIOS QUE SE HAN DE DISTRIBUIR ANUALMENTE}

1.

Siendo de mucha emulación el mejor atractivo para el fomento de todas las Artes y Ciencias para que no falte en este establecimiento interín logra fondos con que extenderse sus ideas se señalan por ahora en cada año seis premios, el primero de 140 pesos, el segundo de 80 pesos, el tercero de 60 pesos, el cuarto de 20 y el sexto de 10 que se distribuirán en esta forma.

\section{2.}

Los tres de ciento cuarenta, ochenta y sesenta son solo reservados para los que por medio de alguna invención máquina o otra cualesquiera industria contribuya a el mejor trabajo de las minas, beneficio de metales por fundición o azogue ya sea en la mejor construcción de hornos, modos de disminuir las pérdidas de la lava y en general en 
todo lo que sea útil a este exercicio ahorro de gastos y mayores productos.

3.

A estos premios se admitirán indistintamente de dentro y fuera de este mineral sin diferencia de clases ni sexos y los que aspiren a conseguirlos deberán presentar su proyecto por escrito entregándolo cerrado firmado (34r) y rubricado en la cubierta al secretario de la Academia quien lo hará presente en ella en la Junta del mes de septiembre de cada año para que abriéndose en ella haya tiempo de hacer las experiencias que acrediten la idea del autor antes del fin de año.

4.

Hechas las experiencias que se juzgaren practicables y reconocidos sus efectos en la Junta General de fin del año se leerán todas las memorias que de esta especie se hayan presentado y dada noticia de sus respectivas experiencias se adjudicarán si lo hubieren merecido los tres premios a los tres sujetos que hayan sobresalido según el dictamen de los que han de votar.

5.

Las memorias que por haberse presentado tarde o por el demasiado tiempo que pida sus experiencias no puedan acreditarse con estar antes del fin de año quedarán reservadas para el siguiente.

6.

Aquellos sujetos a quienes no puede servir de (34v.) incentivo el interés pecuniario y lo será mayor de su gloriosa atención a promover tan laudables fines se presentaren alguna memoria de esta especie contribuyeren con alguna suma u otro don a la Academia se les remunerará poniéndolos en el número de sus individuos supernumerarios.

7.

Los otros tres premios se distribuyan entre los Discípulos del primer año después del examen que en fin de el se hagan adjudicándolos a los tres que más hayan aprovechado interín hay Discípulos de segundo y tercer año a quienes también se propondrá entonces su respectivo premio.

\section{TÍTULO $6^{\circ}$ \\ FORMA DE ELECCIONES Y VOTOS QUE PARA ELLAS Y DEMÁS ASUMPTOS HAN DE CONCURRIR \\ 1.}

Para las elecciones de censor, secretario (35r.) diputado, maestros y discípulos comunicaran los doce individuos de número fixo que quedan establecidos en cuya clave entraran aunque pasen de este número todos los que ahora para la formación se señalan y el censor cuando no sea de entre los mismos.

2.

Todos estos también tendrán voto en la Juntas particulares de cada mes en los asuntos que en ellas se traten sobre el gobierno de la Academia y Escuela y también en la adjudicación de los premios señalados en el título anterior cuya votación se hará en junta particular antes de la pública en que se han de leer las memorias y dar noticias de los premiados.

3.

Las elecciones se harán a pluralidad de los votos pero para la adjudicación de premios habrán de concurrir las dos partes a favor del premiado y en lo respectivo a disposición de caudales se determinara en Junta y será precisa la conformidad de todos los vocales.

\section{(35v.)}

4.

Para las juntas mensuales no se ha de citar por quedar ya determinado el jueves primero de cada mes para ellas y la hora será la que en la primera se estime más cómoda para todos pero a las dos publicadas de junio y diciembre se citará al día antes por el escribano de la Academia que lo será el de minas y lo mismo si se ofreciere aluna extraordinaria.

5.

Dando fe el escribano de haber citado, se tratarán los asumptos sin respeto a los ausentes que deberán quedar ligados a la común resolución sin poder impugnarlas con ningún pretexto.

6.

En la adjudicación de premios y materias propias de su profesión tendrán voto los maestros pero en las elecciones y todo lo que sea puramente gubernativo y económico solo lo tendrán los individuos antes señalados. (36)

\section{TÍTULO $7^{\circ}$ \\ FONDOS DE LA ACADEMIA, SU DESTINO FORMALIDADES PARA DARSELO Y CUENTAS QUE DE ELLOS SE HAN DE DAR \\ 1.}

No teniendo por ahora otro fondo fixo que el de la voluntaria contribución que se han obligado los individuos del ilustre Gremio para la dotación de Maestro para darle alguno con que pueda por el pronto ayudar a los gastos que han de ser indispensables se le aplican los arbitrios siguientes. 
2.

Siendo notoria la costumbre que hasta el ingreso del actual gobierno se había observado por muchos años de cobrar todos los meses a cada pallaquero dos pesos por la revalidación de su licencia, y conociéndose por la experiencia que el haber quitado este abuso ha generado en la perjudicial libertad de trabajar todos sin licencia y destruir los caminos del cerro con daño irreparable de las minas y los que la trabajan para obviar estos inconvenientes y fomentar el trabajo de las minas coartando el de los pallacos se volverá ( $36 \mathrm{v}$ ) desde el mes siguiente a entablar la antigua cobranza y todo su producto con razón jurada se hará presente en la junta de cada mes para que a presencia de todos se pase al tesorero a excepción de los que según la cantidad a que ascienda parezca justo asignar al alcalde veedor que se destine para executar la cobranza con la fidelidad debida y sin extracción de los que han de sufrir por beneficio del bien común a que se aplica.

3

Del mismo modo dando el escribano de minas al de cada mes certificación de todas las actuaciones que en el discurso de el haya habido concernientes al registro de ellas, licencias de despoblados, pallacos, todos aquellos derechos que por arancel están señalados a el juez y habiéndose cobrado siempre habían dejado de percibirse por el actual gobernador volverán a cobrarse por el mismo escribano que los presentara con la certificación que acredite su valor en la junta de cada mes para que a vista del tesorero (37)

4.

A más de estos fondos que únicamente han podido hallarse sin perjuicio del público ni pensión de los interesados se aplicaran da los mismos los cien pesos ofrecidos por este juzgado y las demás cantidades que puedan ofrecerse por los que celosos del bien público se interesen en su fomento, las cuales deberán entregarse en la Junta mensual a presencia de todos y en la inteligencia en que nada varia el mérito la mayor o menor cantidad porque solo se atiende el laudable fin de su destino y celo de quien la ofrece sin que esto impida el que la junta añada a el número de sus individuos aquellos a quienes por la extraordinaria circunstancias de su generosidad juzgue preciso distinguirlos como a particulares bienhechores.

5.

Estos caudales han de sufragar para los gastos de libros en lo sucesivo y todos lo que el Secretario y Tesorero puedan tener por razón de su oficio que en nada les han de ser gravosos ( $37 \mathrm{v}$.)

6.

Estando el actual Maestro dotado de otros ramos que la generosidad del ilustre Gremio y celo del Director han proporcionado y no han de entrar por ahora en los fondos de los expresados se sacará para los premios anuales que quedan establecidos en caso de haber quien los merezca.

7.

De los mismos fondos se suministrará a el Maestro alguna ayuda de costa para aquellos gastos que en las experiencias de s casa pueda ser precisos en la inteligencia de que en los ensayes que a beneficio de un particular hagan los ha de costear el mismo invirtiéndose en el fondo el poco o mucho producto que den de si estas privadas operaciones.

8.

Como las experiencias que en cada ingenio deben practicarse ceden en beneficio de su cargo los gastos en la forma expresada para hacer más llevadera esta levísima pensión que solo (38) lo será por aquel corto aumento o pérdida que tal vez pueda resultarle a lo que había de gastar y sacar del mismo cajón por el método ordinario.

9.

No siendo posible prescribir ahora todos los usos a que puedan aplicarse los caudales según el tiempo vaya dictando en consideración a los que se acopien y adelantamientos que se reconozcan bastará prevenir en general que en ningún caso se han de invertir en otros fines que los que miren el común beneficio ya sea para dotación de otros maestros que puedan contemplarse convenientes ya sea para compra de libros u otros instrumentos necesarios o para adelantar la fundación a aquellos objetos de que ahora por la imposibilidad no se ha tratado.

10.

Ningún empleo ha de tener ni pretender sueldo incluso el mismo Presidente Director y solo al Tesorero en lo sucesivo podrá asignársele el que parezca juntos a vista del manejo de caudales que puedan juntarse y su distribución en que ahora entra sin ninguno por la cortedad de ellos (38v) el nombrado habiendo este servicio al público en correspondencia de la confianza con que se le mira 11.

Todas las libranzas que se expidan han de ir firmadas por el Director y Diputados de la Academia y intervenida por el Secretario que el libro de fondos 
tomará razón de ellas, expresándolo al pie de la misma libranza y sin estas formalidades no las pagará el Tesorero ni se le abonarán en sus cuentas.

12.

En fin de cada año presentará el Tesorero en Junta de todos los vocales su cuenta general de cargo y data documentadas con las libranzas para que cotejadas con el libro del Secretario se le de aprobación correspondiente y sabiéndose el residuo se le ponga este por primera entrada y cargo en el nuevo libro guardándose el del año anterior con sus respectiva cuenta en el archivo.

\section{TÍTULO 8 \\ LIBROS QUE HAN DE HABER SU DESTINO LUGAR DE SU CUSTODIA Y DE LAS JUNTAS}

(39)1.

Suponiendo que todos los libros han de ser limitados para el curso del año habrá uno en que dándose razón en la Junta de cada mes del caudal que pueda haberse atesorado se sentaran las partidas para por ellas formar cargo al tesorero y del mismo modo se pondrán las libranzas que se expidan con expresión de los usos a que son destinadas.

2.

Otro libro servirá para escribir lo que en las Juntas de cada mes y otras extraordinarias pueda acordarse sobre el gobierno de la Academia y Escuela y economía de sus fondos poniendo el principio de cada año individuos así de número fixo como supernumerarios que haya hasta entonces.

3.

Del mismo modo en Libro separado se sentaran las experiencias que se executen explicando con toda individualidad el método que en ellas se ha seguido sus efectos y demás que contribuya a que con el tiempo se vaya insensiblemente formando una conexión de memorias y experimentos $(39 \mathrm{v})$ en que sea fácil distinguir los infructuosos de los útiles y tener todas las noticias que puedan importar así para el uso de los unos como para el desengaño de los otros, y adelantamientos que en todos pueda discurrir la aplicación.

4.

En otro libro se sentaran los discípulos que anualmente entren se anotaran su deserción si faltare antes de cumplir el tiempo y se apuntaran los exámenes del fin del año y aprobación expresando los que han llevado el premio y escribiéndolos por el orden mismo de su aprovechamiento para que conste el de cada uno por la misma graduación de su número.

5.

Amas de estos libros se formará por meses y unirán en un volumen todas las memorias proyectos o invenciones que puedan presentarse en el discurso del año anotando en fin de él las que hayan obtenido el premio.

6.

Todos estos libros y papeles que han de formarse (40) por el modelo de los que ahora se presentan con el original de las constituciones autorizado por el escribano de la Academia y firmado del director se guardaran en el archivo de ella a lo que se destinara una pieza decente y la correspondiente seguridad.

$$
7
$$

La llave del archivo la tendrá el secretario y por su ausencia y enfermedad la entregara al director para que en las juntas y ocasiones que en el interín pueda ofrecerse haga el secretario indistintamente cualquiera de los individuos de numero fixo que concurran.

8

Se formará un índice de todos los libros y papeles que haya en la Academia y sucesivamente vayan aumentándose y en fin de cada año se leerá y cotejará para precaver su extravío.

9

En la misma sala serán las juntas mensuales y las públicas a menos que el concurso de ellas haga preciso celebrarlas en otro sitio de mayor extensión que se proporcionara según pidan las circunstancias.

Finis (41)

LISTA DE LOS S.S. QUE SE SEÑALAN POR INDIVIDUOS DE LA ACADEMIA EN SU PRIMERA FORMACIÓN CON EXPRESIÓN DE SUS OFICIOS.

\section{DIRECTOR}

El Sr. Dn. Jorge de Escobedo y Alarcon como superintendente del Banco

El Sr. Conde Casa Real de Moneda

El Sr. Brigadier Dn. José de Montes

CENSOR

El Sr. Dr. Dn. José Suero y Andrade

El Sr. Alcalde Provincial D. Joaquín Bravo de Bobadilla

El Sr. Dn. Juan de Peñarrubia

SECRETARIO

El Sr. Dn. Joaquín de Otondo 
Diputados del gremio

Sr. Dn. Paulino Matienzo

Sr. Dn. Fermín Prudencio

Sr. Dn. Diego Domínguez. Oficial real

Sr. Dn. Josef Elorga, procurador de la villa

Sr. Dn. Joaquín Yáñez, Director $1^{\circ}$ del socavón

Sr. Dn. Juan José Pérez Navarro, ensayador de las

Rs. Cajas

Sr. Dn. Pedro Masondo, primer ensayador de la

Real Casa de Moneda
Sr. Dn. Raymundo de Yturriaga. Ydem $2^{\circ}$

Sr. Dn. Hilario Malaver

TESORERO

Dn. José Xavier de Yturriaga que lo es del Banco

MAESTRO

Dn. Antonio Silva

ESCRIBANO

Dn. Pedro Toro y Maldonado, que lo es de Minas

\section{Referencias Citadas}

Bargalló, Modesto

1955 La minería y la metalurgia en la América española durante la época colonial, Fondo de Cultura Económica, México.

Barba, Alonso

1993 El arte de los metales. [1640], Editorial París-Valencia, Valencia, España.

Böttcher, Hausberguer y Max Hering (Comps.)

2011 El peso de la sangre. Limpios, mestizos y nobles en el mundo hispánico, El Colegio de México, México.

Buechler, Rose Marie

1773 "Technical aid to Upper Peru: the Nordenflicht expedition”, en Journal of Latin American Studies, Vol. V, № 1 . Cambridge University Press, pp. 33-77.

1989 Gobierno, Minería y Sociedad. Potosí y el Renacimiento Borbónico, 1776-1810, Biblioteca Minera Boliviana, La Paz.

Cano Borrego, Pedro Damián

2016 "La Moneda en el Reino de Guatemala durante el siglo XVIII" en Anuario de Estudios Centroamericanos. N. 42, Universidad de Costa Rica.

Escamilla, F. Omar y Lucero Morelos

2017 Escuela de Minas Mexicanas, 225 años del Real Seminario de Minería, UNAM, México.

Fernández Alonso, Serena

1992 "Perfil biográfico y acción de gobierno de don Jorge Escobedo y Alarcón”, en Revista de Indias, No 195/196, CSIC. Madrid.

Flores Clair, Eduardo

2000 Minería, educación y sociedad. El Colegio de Minería, 1774-1821. Instituto Nacional de Antropología e Historia, México.

2001 El Banco de Avío Minero Novohispano. Crédito, finanzas y deudores, Instituto Nacional de Antropología e Historia, México.

Gato Castaño, Purificación

1994 "La academia de metalurgia de Potosí, obra del ilustrado Jorge Escobedo, 1775-1785”, en Castillo Martos (coord.), Minería y Metalurgia, Intercambio tecnológico cultural entre América y Europa durante el periodo colonial español, Muñoz Moya y Montraveta Editores, Sevilla-Bogotá.

Gavira Márquez, María Concepción

2007 "Política minera y conflictos entre Potosí y Oruro a principios del siglo XVII", en Revista Tiempos de América, N. 14, pp. 3-20, Universidad Jaume I, Castellón, España.
2011: "El mineral de Chayanta: la sublevación indígena de 1781 y el auge minero", en Diálogo Andino, №37, pp. 25-44. 2013 Minería en Chayanta. La sublevación indígena y el auge minero, 1775-1792, Plural Editores, La Paz.

2013b "Instrucciones para los subdelegados de la intendencia de Potosí realizadas por el intendente Juan del Pino Manrique en 17842", en Diálogo Andino, Universidad de Tarapacá, Chile, $\mathrm{N}^{\circ} 42$, pp. 5-16.

Hausberger, Bernd

2009 "El universalismo científico del Barón Ignaz von Born y las Transferencia de tecnología minera entre Hispanoamérica y Alemania a fines del siglo XVIII", en Historia Mexicana, V. 59, Colegio de México, México.

Humboldt, Alexandro

1991 Ensayo político sobre el reino de la Nueva España [1811]. Porrúa, México.

Izquierdo, José Joaquín

1958 La primera casa de las ciencias en México, el Real Seminario de minería (1792-1811), Ciencia, México.

Molina Martínez, Miguel

1977 "La formación técnica del minero peruano y los proyectos de un Colegio de Minería", en Boletín del Instituto Riva-Agüero, n. 11, Lima, pp. 125-146.

Muñoz Dueñas, María Dolores

1992 "La formación de una élite minera: la Escuela de minas de España (1777-1877)", Melanges de la Casa de Velázquez, Madrid, pp. 21-36.

Ovando Sanz, Guillermo

1975 La Academia de minas de Potosí, 1757-1970, Banco Central de Bolivia, La Paz.

Palacios Remondo, Jesús

1994 "Fausto y Juan José Delhuyar en Europa y su reflejo en la minería novohispana", en Castillo Martos (coord.), Minería y Metalurgia, Intercambio tecnológico cultural entre América y Europa durante el periodo colonial español, Muños Moya y Montraveta Editores, Sevilla-Bogotá.

Platt, Tristán

1999 "La alquimia de la modernidad. Los fondos de cobre de Alonso Barba y la Independencia Metalúrgica boliviana (1780-1880)", en Anuario. Archivo y Biblioteca Nacionales de Bolivia, 1999, la Paz.

Sánchez Gómez, Julio

1997 "La Técnica en la producción de metales monedables en España y América, 1500-1650”, en Julio Sánchez 
et al., La sabia del imperio, Universidad de Salamanca, Salamanca.

Sonneschmidt, F.

1985 "El método de amalgamación", en Elías Trabulse, Historia de la Ciencia en México, Estudio y Textos, siglo XVIII, Conacyt y Fondo de Cultura Económica, México.

Sumozas García-Pardo, Rafael

2007 Arquitectura industrial en Almadén: antecedente, génesis y repercusión al modelo de la minería americana. Universidad Castilla-La Mancha y Universidad de Sevilla, Sevilla.
Tandeter, Enrique

1992 Coacción y Mercado. La minería de la Plata en el Potosí colonial, 1692-1826, Editorial Sudamericana, Buenos Aires.

\section{Fuentes}

Archivo General de Indias, Sevilla (AGI).

Audiencia de Charcas, legs. 425, 435, 438, 437 A, 437 B, 470, 700 .

Archivo Histórico del Palacio de Minería, México (AHPM). Año 1803, II-120-d. 6.

\section{Notas}

$1 \quad$ En "El método de amalgamación", escrito por Sonneschmidt señala: "Conviene por tanto que se extienda su conocimiento en la Europa para hacer justicia a este sobresaliente método que la preocupación europea ha tratado con bastante desprecio", en Elías Trabulse, Historia de la Ciencia en México, Estudio y Textos, siglo XVIII.

2 Los dos apoderados del gremio minero presentaron un informe titulado: Representación que a nombre de la minería de la Nueva España hacen al rey nuestro señor los apoderados de ella. Véase José Joaquín Izquierdo, 1958: 18.

3 Francisco Xavier Gamboa en los Comentarios a las Ordenanzas de Minería ya manifestaba la falta de preparación de los operarios pero no planteó un colegio formal como obligación del Estado para solucionar el problema. Véase Eduardo Flores Clair, 2000: 24.

4 AGI, Charcas, 470. Expediente 29 y 30, fechas $1757-$ 1762. Santélices se interesaba especialmente por mejorar el beneficio de metales "negrillos". Decía el gobernador haber conseguido en estos experimentos en el ingenio Cuti sacar 20 marcos de los metales negrillos que antes habían producido 8 marcos.

5 Ovando Sanz (1975: 5) realiza la siguiente distribución pero sin dar referencia documental: profesor de química: Irigoyen y Domingo Serrano, profesores de explotación: Joaquín Bravo y Joaquín Neish, profesores de metalurgia: Domingo Tenorio y Juan Bautista de Lacoa.

$6 \quad$ El beneficio de este tipo de metales muy frecuente en Potosí era una preocupación que ocupaba a los expertos desde el siglo XVI. Según Julio Sánchez (1997: 152), en 1600 la Audiencia de Charcas solicitaba ayuda de los expertos alemanes para el tratamiento de estos metales.

7 Jorge Escobedo y Alarcón nació en Jaen en 1755 y falleció en Madrid en 1808, fue uno de los políticos ilustrados más importantes del reinado de Carlos III. Hijo de los condes de Cazalla inició sus estudios de jurisprudencia civil y canónica y bellas artes en el Colegio Mayor de Cuenca. Opositó a la cátedra de Filosofía moral de la Universidad de Salamanca en 1769 y siete años después fue nombrado oidor de la Audiencia de Charcas. Ejerció importantes cargos en el virreinato del Perú y Río de la Plata, fue gobernador de Potosí, visitador general y superintendente de Real Hacienda en el virreinato peruano. Fernández Alonso (1992).

8 Este discurso y las Ordenanzas de la Academia forman parte de un mismo cuadernillo de 42 fojas (AGI. Charcas,
425). Podemos encontrar una transcripción en Guillermo Ovando Sanz (1975, pp. 80-94) y Purificación Gato Castaño (1994, pp.175-204) realiza un breve análisis.

9 Flores Clair (2000: 32). Juan Lucas Lassaga murió en febrero de 1786 y un mes más tarde Joaquín Velázquez de León. Ese mismo año el rey designó a Fausto de Elhuyar como director general pero no llegó a la Nueva España hasta 1788.

10 AGI, Charcas 437 A. Carta de Escobedo a Areche, Potosí 21 de junio de 1779. "Estos discípulos pobres e incapaces de su subsistencia no la pueden tener en la escuela y aun alguno estoy yo costeando de mi bolsillo por caridad y porque no deserten todos como ya han hecho algunos".

11 Acerca del impacto de Alonso Barba en la región véase el trabajo de Platt (1999) donde analiza el renacimiento del método de beneficio por cocimiento inventado por Barba en centros mineros del Alto Perú desde fines del siglo XVIII, cobrando más importancia en las primeras décadas de la República.

12 El 20 de diciembre de 1781 la junta de la Academia analizó la petición de un grupo de azogueros de Porco para que se le permitiera al maestro Antonio Silva continuar los experimentos con el beneficio de negrillos en Porco y para ello estaban dispuestos a contribuir con 4 reales semanales a los fondos de la Academia. AGI, Charcas, 438. № 140. Escobedo a Gálvez, Potosí, 16 de enero de 1782.

13 Respecto de la comisión de los expertos europeos en el virreinato del Río de la Plata hay diferentes estudios que analizan las condiciones en que se pretendía "modernizar" la tecnología metalúrgica americana y la falta de resultados de la aplicación del método de beneficio de Born. Pueden consultarse diferentes trabajos para su estancia en Potosí: Buechler (1973 y 1989), Tandenter (1992), Platt (1999) Hausberger (2009).

14 La rebelión indígena de 1780 afectó en gran medida el Alto Perú donde se ubicaban los principales centros mineros, pero estudios que hemos realizado sobre Chayanta nos han evidenciado que esta coyuntura no fue determinante en cuanto a la producción de plata de algunos centros mineros, pues en este corregimiento se manifestaba un auge en la plata registrada durante los años inmediatos y posteriores a la rebelión katarista (Gavira 2013).

15 AGI Charcas, 438. Índice de las cartas que el gobernador Intendente de Potosí dirige por vía reservada con fecha 16 de septiembre de 1787. Documento 33. 
